\title{
Fusarium moniliforme (Sheldon) Isolated from Gills of Kuruma Prawn Penaeus japonicus (Bate) with Black Gill Disease
}

\author{
Winai Rhoobunjongde, ${ }^{*}$ Kishio Hatai, ${ }^{*}$ Shinpei Wada,* \\ and Saburoh S. Kubota* \\ (Received October 2, 1990)
}

\begin{abstract}
Fusarium moniliforme was isolated from gill lesions of kuruma prawn Penaeus japonicus, with black gill disease at a private farm in Okinawa Prefecture in 1989. The colonies of the fungus cultured on upper surface of potato dextrose agar were floccose, creamy white, undersurface a lavender to violet, but did not grow on mycobiotic agar containing cycloheximide. The present report describes the first case of $F$. moniliforme infection in crustacea. An experimental infection using kuruma prawn was made by intramuscular injection with the conidia of $F$. moniliforme $\mathrm{NJM}$ 8995. For comparison, Fusarium solani NJM 8996 isolated also from a kuruma prawn with black gill disease in Okinawa Prefecture in 1989, was used as a reference. The clinical signs and pathological findings of the disease caused by the two species of the fungi were similar. Identification of the fungi isolated from the lesions was based principally upon the cultural characteristics. The use of a media lacking cycloheximide is recommended for the isolation of $F$. moniliforme.
\end{abstract}

Cultured kuruma prawns Penaeus japonicus suffering from black gill disease were sampled from a private farm in Okinawa Prefecture in 1989. This disease was originally observed by Egusa \& Ueda ${ }^{1}$ and the causative agent was identified as Fusarium solani by Hatai et al. ${ }^{2)}$ Only one species of the genus Fusarium, F. solani, has so far been identified as the pathogen causing black gill disease in the kuruma prawn. F. solani is a comparatively well documented species with detailed examinations of its pathogenicity, ${ }^{3-9)}$ pathogenesis ${ }^{10)}$ and histopathology. ${ }^{11-13)}$ The present study describes a case of Fusarium infection in a kuruma prawn caused by Fusarium moniliforme, which has never been reported from crustaceans as a pathogen.

The clinical signs of the diseased prawns showed many black spots on their gills which occasionally fused to a stone-like mass in advanced stages (Fig. 1). In the early stages, the gills appeared to show a slight change in colour from opaque white to a yellow or brown colour prior to black spots developing. Fresh mounts prepared from infected gills typically contained hyphae (Figs. 2,3) and two kinds of conidia. The fungus was classified in the genus Fusarium from the shape of the characteristic macroconidia.

The conidia of $F$. moniliforme were intramuscularly inoculated to prove whether the isolated fungus was capable of causing black gill disease and death in prawns. The histopathological examinations were also made on naturally and experimentally infected prawns.

\section{Materials and Methods}

\section{Fungal Isolation and Identification}

The moribund kuruma prawn Penaeus japonicus were obtained from a private farm in Okinawa Prefecture in April 1989. Isolation of fungus was made by incubating a small piece of gill from a diseased kuruma prawn onto Potato Dextrose Agar "Eiken" (PDA) containing $500 \mu \mathrm{g} / \mathrm{m} /$ each of penicillin $\mathrm{G}$ and streptomycin and also onto Mycobiotic agar "Difco" (MBA) at $25^{\circ} \mathrm{C}$. A piece of an agar (PDA) block with mycelium was cut out and transferred onto PDA to obtain a pure culture. The isolated fungus was identified according to Booth ${ }^{14)}$ and Nelson. ${ }^{153}$ Furthermore the potassium chloride $(\mathrm{KCl})$ medium was used to observe typical long chains of microconidia.

\section{Histopathology}

Gills were fixed in $10 \%$ phosphate-buffered formalin solution, embedded in paraffin, sectioned and then stained with haematoxylin and eosin (H \& E), periodic acid Schiff's stain (PAS) and Grocott, using routine histological methods.

* Nippon Veterinary and Animal Science University, Musashino, Tokyo 180, Japan (W. Rhoobun-

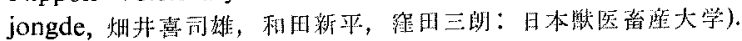



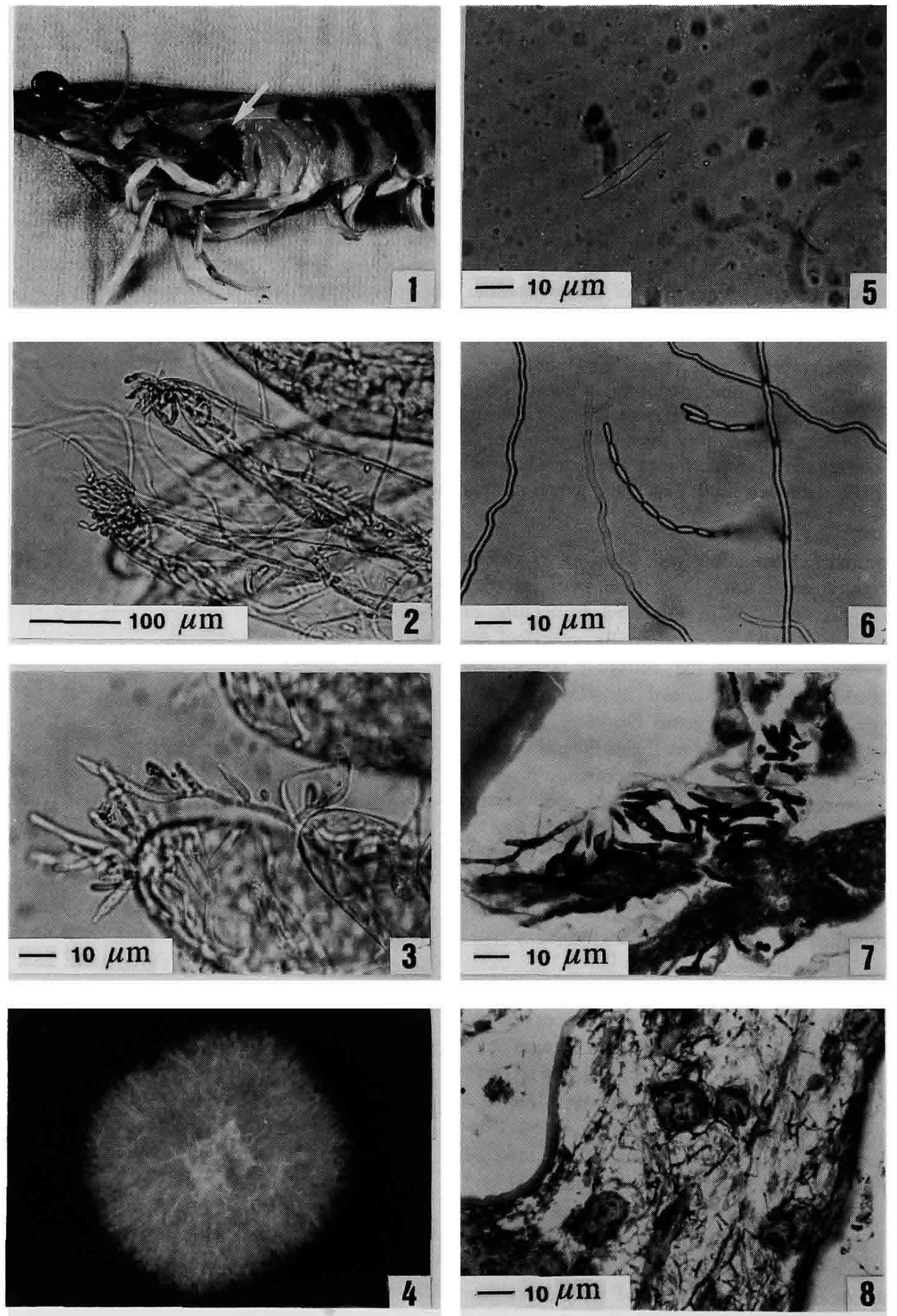


\section{Artificial Infection}

A strain (NJM 8995) of the present fungus $F$. moniliforme was used for an artificial infection. Fusarium solani NJM 8996, isolated from a kuruma prawn with black gill disease at a farm in Okinawa Prefecture in 1989, was used for comparison with $F$. moniliforme. Both strains were cultured on PDA at $25^{\circ} \mathrm{C}$. After 2 weeks of incubation, $10 \mathrm{ml}$ of sterile artificial seawater was added onto the plates to obtain the conidial suspension for both strains. The number of con idia in the final suspension was adjusted to approximately 800 and 80,000 conidia per $\mathrm{m} l$ of sterile artificial seawater for the both strains. Healthy cultured kuruma prawns of $15-28 \mathrm{gm}$ in body weight and $12-15 \mathrm{~cm}$ in body length with no visible black spots in the gills, obtained from Kagoshima Prefecture, were used for the aritificial infection. The experimental prawns were allotted into 5 groups of 20 prawns each, and they were injected intramuscularly at the site of the third somite of the abdomen with $0.1 \mathrm{~m} l$ of the conidial suspension mentioned above. Ten prawns were used as a control. The conidia injected prawns and control prawns were kept separately in plastic tanks containing 150 litre of seawater without sand at the bottom and maintaining in recirculation by flowing seawater outside the tanks. During the course of the experiment, all prawns were not fed. Mortality of the prawns, seawater temperature and salinity were recorded every day. Seawater temperatures varied between $19-22^{\circ} \mathrm{C}$ and salinity ranged from 24 to $32 \%$. Two prawns were randomly removed to observe the gill condition and the fungal infection under microscope at $1,4,7$, and 14 days after inoculation. Attemps were made to isolate the inoculated fungus from their gills, and fix the gills in $10 \%$ phosphatebuffered formalin solution for the histopathological observations.
Effect of Cycloheximide and Temperature on the Growth

Each agar block with the mycelium at the edge of growing colonies of both strains, $F$, moniliforme NJM 8995 and $F$, solani NJM 8996, after 7 days of incubation were removed using a No. 2 cork borer approximately $5.5 \mathrm{~mm}$ in diameter and put onto he center of the PDA plates containing cycloheximide at concentrations of $0,25,100$ and $400 \mathrm{ppm}$. These agar plates were incubated at $25^{\circ} \mathrm{C}$. Further, agar blocks with mycelia of the two isolates were put onto the center of the PDA plates and incubated at various temperatures 5 , $10,15,25,30$ and $37^{\circ} \mathrm{C}$. For both experiments, the same procedures were repeated four times to measure the growing colonies in $\mathrm{mm}$ of diameter at 4,7 and 10 days after inoculation.

\section{Results}

\section{Fungal Isolation and Identification}

A fungal species was isolated from the inoculated material (Fig. 4). The colnial size of the fungus grown on PDA at $25^{\circ} \mathrm{C}$ was approximately 35,53 and $65 \mathrm{~mm}$ in diameter at 4,7 and 10 days after inoculation, respectively. The fungus was classified to the group of the rapidly growing fungus. The colony on PDA was floccose, initially creamy white in colour, then darkened to a lavender colour as it grew, becoming violet in the center and lavender at the margin within 2 weeks. No growth was observed on MBA that contained cycloheximide. Cycloheximide at the concentration of $400 \mathrm{ppm}$ in MBA was effectively able to inhibit growth of the fungus.

Fungal hyphae were hyaline and $2.5-6.0 \mu \mathrm{m}$ in diameter. Conidiogenous cells with long monophialides were abundantly formed laterally on aerial mycelium or on sympodially branched conidiophores, and were hyaline, subulate 2.0

Fig. 1. Gross appearance of the gills of a naturally infected kuruma prawn Penaeus japonicus. Note: necrotic tissue fused to a stone-like mass (arrow).

Fig. 2. Fusarium moniliforme in the gills of a naturally infected kuruma prawn showing hyphae growing out from the tip of gill filament, producing conidiophore and conidia. Fresh mount.

Fig. 3. The same lesion as Fig. 4. at high magnification.

Fig. 4. Colony on Potato Dextrose Agar (PDA) 4 days after inoculation.

Fig. 5. Six-celled macroconidia and one-celled microconidia of $F$. moniliforme producing by aerial hyphae growing out from the tip of gill filament. Fresh mount.

Fig, 6. Microconidial chains produced from a conidiophore on $\mathrm{KCl}$ medium 7 days after inoculation, Fresh mount.

Fig. 7. Histology of the macroconidia and hyphae within a gill lamella. Grocott.

Fig. 8. Histological section through a blackened gill branch showing the blockage of brachial blood vessels due to encapsulated fungal conidia and hyphae. Grocott. 
Table 1. Comparison of morphological characteristics of the present isolate (NJM 8995) and $F$. solani isolated from kuruma prawn, Penaeus japonicus with black gill disease and $F$. moniliforme reported by several workers

\begin{tabular}{|c|c|c|c|}
\hline Characteristics & $\begin{array}{l}\text { Present strain, } \\
\text { NJM } 8995\end{array}$ & F. solani ${ }^{* 1}$ & F. moniliforme $e^{* 2}$ \\
\hline \multirow[t]{2}{*}{ Colony } & $\begin{array}{l}\text { White aerial mycelium } \\
\text { grows rapidly }\end{array}$ & $\begin{array}{l}\text { White aerial mycelium } \\
\text { grows rapidly }\end{array}$ & $\begin{array}{l}\text { White aerial mycelium } \\
\text { grows rapidly }\end{array}$ \\
\hline & Undersurface violet & Undersurface brown & Undersurface violet \\
\hline Conidiophores & $\begin{array}{l}\text { Long unbranched and } \\
\text { branched } \\
\text { monophialides }\end{array}$ & $\begin{array}{l}\text { Long unbranched and } \\
\text { branched } \\
\text { monophialides }\end{array}$ & $\begin{array}{l}\text { Long unbranched and } \\
\text { branched } \\
\text { monophialides }\end{array}$ \\
\hline \multicolumn{4}{|l|}{ Macroconidia } \\
\hline Length $(\mu \mathrm{m})$ & $26-50$ & $30-45$ & $25-60$ \\
\hline $\begin{array}{l}\text { No. of cells } \\
\text { range (usually) }\end{array}$ & $4-6(4)$ & $46(4)$ & 48 \\
\hline Shape & Cigar & Canoe & Cigar \\
\hline \multicolumn{4}{|l|}{ Microconidia } \\
\hline Length $(\mu \mathrm{m})$ & $6-12$ & $6-10$ & $5-12$ \\
\hline $\begin{array}{l}\text { No. of cells } \\
\text { range (usually) }\end{array}$ & $1-2(1)$ & $1-3(1)$ & $1-2(1)$ \\
\hline Shape & Fusoid or clavate & $\begin{array}{l}\text { Ovoid, oblong or } \\
\text { slightly curved }\end{array}$ & Fusoid or clavate \\
\hline Form & Cluster, long chains & Only cluster & Cluster, long chains \\
\hline Clamydospore & Absent & Present & Absent \\
\hline \multicolumn{4}{|l|}{ Hyphae } \\
\hline Diameter $(\mu \mathrm{m})$ & $2.5-6$ & $3-4.5$ & - \\
\hline Cycloheximide & Sensitive & Resistant & Sensitive \\
\hline
\end{tabular}

$4.0 \mu \mathrm{m}$ in diameter. Macroconidia were present but only rarely and their appearance varied from slightly sickle- to cigar-shaped, 3-4 septa, rarely 5 septa and $26.0-50.0 \mu \mathrm{m}$ in length (Fig. 5). Microconidia were abundant and variable on shape and size from ovoid to elliptical, 0-1 septa, rarely 2 septa, $6.0-20.0 \mathrm{~km}$ in length, and were produced in chains mostly from a simple conidiophores (Fig. 6) and false heads on PDA and $\mathrm{KCl}$ medium but especially with longer chains on the $\mathrm{KCl}$ medium. Clamydospore was absent. Morphological characteristics of the isolate are listed in Table 1, comparing with those of $F$. solani described by Egusa \& Ueda, ${ }^{12}$ Hatai, ${ }^{2)}$ and F. moniliforme described by Booth, ${ }^{14\rangle}$ Nelson, ${ }^{15)}$ Young $^{10)}$ and Frelier ${ }^{17)}$ On the basis of these characteristics, this culture was identified as Fusarium moniliforme of the section Liseola. ${ }^{14,15)}$

\section{Histopathology}

Fungal hyphae and occasionally 1-2 celled microconidia and 4-6 celled macroconidia were observed in the collapsed gills (Fig. 7). Both types of conidia were also observed on the external hyphae which were growing out of the gill filament. Thrombosis caused by clotted haemocytes and hyphae, typically encapsulated by melanized multiple layers of fusiform haemocytes and fibrocytes, were found in the haemocoel of the gill axes and branches (Fig. 8). Furthermore, the latter was surrounded by amorphous mass of substances caused by coagulative necrosis.

\section{Experimental Infection}

In the early stage of the infection, no fungal elements were observed under light microscope in the gills of the dead prawns and no growth of hyphae on the PDA also developed at $25^{\circ} \mathrm{C}$. The inoculated fungus was able to reisolate from the gills from 4th day of post-inoculation. Prawns which died prior to this 4 th day were not included in the mortality data.

As shown in the Fig. 9, the prawns injected with the lower concentration of the conidia ( 80 conidia/prawn) of $F$. moniliforme NJM 8995 and $F$. solani NJM 8996 first showed mortality 8-9 days after inoculation. The mortality rate of prawns infected with the $F$. moniliforme was slightly higher than that of the $F$. solani. However, the prawns injected with the large number of the conidia $(8,000$ conidia/prawn) of the both strains died 4 days after inoculation and all the prawns finally died within 2 weeks. The gills infected with both strains 
showed the typical black gills condition variable from sparse brown spots to extensive black. On the contrary, no death occurred in the control prawns, no black spots were observed in the gills, and all prawns were free from the pathogenic fungus during the course of the experiment.

Effects of Cycloheximide and Temperature on the growth

The effects of cycloheximide on the growth of

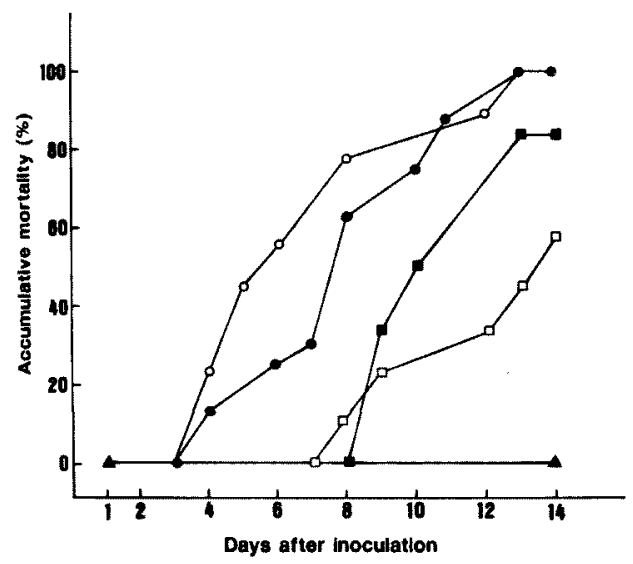

Fig. 9. Mortality rate of kuruma prawns intramuscularly injected with $F$. moniliforme NJM 8995 and $F$. solani NJM 8996 isolated from kuruma prawns at a farm of Okinawa Prefecture.

$O-O \quad 8,000$ conidia of $F$. moniliforme NJM 8995

- 8,000 conidia of $F$. solani NJM 8996

- 80 conidia of $F$. moniliforme NJM 8995

$\square-\square \quad 80$ conidia of $F$. solani NJM 8996

$\Delta-\mathbf{A}$ control.
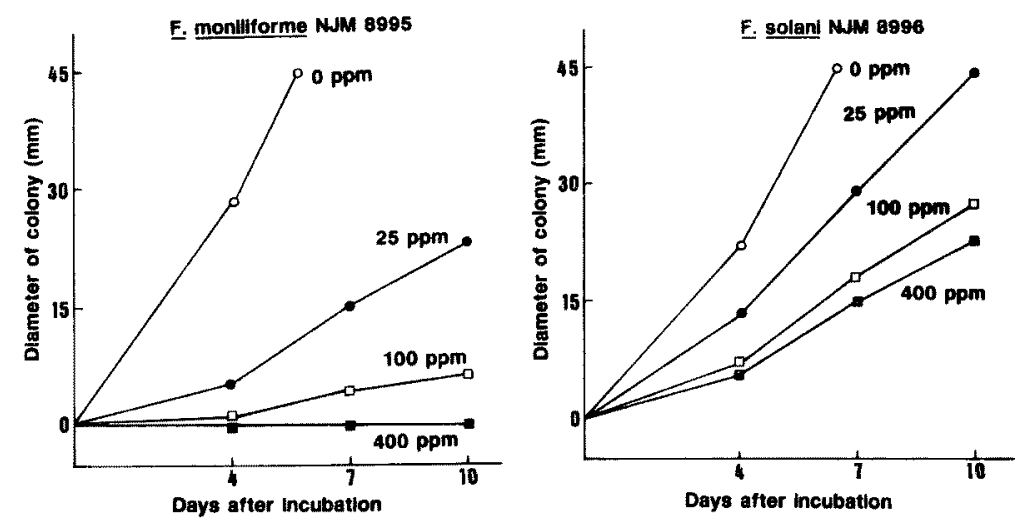

Fig. 10. Growth rate of $F$. moniliforme NJM 8995 and $F$. solani NJM 8996 on PDA containing various amounts of cycloheximide.

$F$. moniliforme NJM 8995 and $F$. salani NJM 8996 are shown in Fig. 10. The $F$. solani was relatively resistant to cycloheximide. The growth of the F. moniliforme was completely inhibited by $400 \mathrm{ppm}$ of cycloheximide.

Effects of the temperature on the growth of F. moniliforme NJM 8995 and F. solani NJM 8996 are given in Table 2. The optimum temperature for both fungi ranged from $25^{\circ} \mathrm{C}$ to $30^{\circ} \mathrm{C}$ with both strains growing slightly at $37^{\circ} \mathrm{C}$, but zero growth was recorded at $5^{\circ} \mathrm{C}$.

\section{Discussion}

Fusarium moniliforme distributes widely in tropical and subtropical regions as a pathogen in various hosts including rice, sugar cane, banana, cotton, maize, etc. ${ }^{14}$ Despite the widespread distribution of $F$. moniliforme, a few cases of the infection with the fungus have been previously reported in man and animals. In man, cases of cutaneous infection, ${ }^{18)}$ systemic infection during treatment for malignant lymphoma ${ }^{18)}$ and the infection after allogenic marrow transplantation ${ }^{18)}$ have been reported. In all cases, the predisposed cause was based on the disturbance of the immune system. In animals, $F$. moniliforme infection has been reported only in a captive alligator Alligator mississippiensis as a fatal pulmonary infection. ${ }^{17}$ In decapod crustacean, Fusarium infection except with $F$. solani, is limited in $F$. tabacinum which infected a crayfish, Austropotamobius pallipes. ${ }^{20)} F$. moniliforme infection in kuruma prawn is the first report as the mycotic disease of crustaceans.

Species identification of Fusarium is difficult 
Table 2. Effects of temperature on growth of 2 species of Fusarium isolated from kuruma prawn Penaeus japonicus

\begin{tabular}{|c|c|c|c|c|c|c|}
\hline \multirow{3}{*}{$\begin{array}{c}\text { Temperature } \\
\left({ }^{\circ} \mathrm{C}\right)\end{array}$} & \multicolumn{6}{|c|}{ Days after incubation } \\
\hline & \multicolumn{3}{|c|}{ F. moniliforme NJM 8995} & \multicolumn{3}{|c|}{ F. solani NJM 8996} \\
\hline & 4 & 7 & 10 & 4 & 7 & 10 \\
\hline 5 & $\mathrm{NG}$ & $\mathrm{NG}$ & NG & $\mathrm{NG}$ & NG & $\mathrm{NG}^{* 1}$ \\
\hline 10 & NG & 1.9 & 4.5 & NG & 0.2 & $0.4^{* 2}$ \\
\hline 15 & 12.8 & 29.3 & 43.6 & 8.3 & 20.6 & 30.5 \\
\hline 25 & 34.4 & 53.2 & 64.3 & 29.1 & 57.9 & 74.6 \\
\hline 30 & 33.8 & 54.0 & 70.8 & 29.6 & 54.5 & 72.2 \\
\hline 37 & 4.7 & 9.9 & 11.5 & 1.7 & 4.8 & 6.3 \\
\hline
\end{tabular}

*I NG; no growth.

*2 Average in diameter of colony ( $\mathrm{mm}$ ).

because of the rapid changes in their morphology and colonial colour. ${ }^{14,15)}$ The most distinctive features of $F$. moniliforme from $F$. solani are the formation of microconidia in chains and the absence of clamydospore. Sometimes the formation of microconidial chains were difficult to observe, and in such a case, the fungus might be wrongly classified to either $F$. oxysporum or $F$. solani. Therefore, the presence or absence of microconidial chains is an important characteristic differentiating species of Fusarium Section Liseola. The $\mathrm{KCl}$ medium to induce the formation of microconidial chains has been used for the identification of $F$. moniliforme and the present isolated produced longer microconidial chains on the medium.

The artificial infection in this study showed the $F$. moniliforme can produce typical black gill condition in kuruma prawn similar to that caused by $F$. solani. The fungus was established as a pathogen of kuruma prawn from the results of the present experiments. The pathogenesis of $F$. moniliforme and the histopathological findings in the kuruma prawn were probably identical to that caused by $F$. solani. Based on the histological observations, failure of gas exchange in the gills was thought to be the main cause of death.

The fungus $F$. moniliforme can not grow on the standard Mycobiotic agar "Eiken" which is usually used to isolate $F$. solani in kuruma prawn. It was suggested that a media lacking cycloheximide should be used together with the standard medium when it was attempted to isolate the causative agant from the lesions showing black gill conditions.

\section{Acknowledgements}

The authors wish to thank Mr. Akira Tsujikado, Mie Prefecture Fish Farming Center, Hamajima,
Mie for supporting the infection experiments.

\section{References}

1) S. Egusa and T. Ueda: Nippon Suisan Gakkaishi, 38, 1253-1260 (1972).

2) K. Hatai, K. Furuya and S. Egusa: Fish Pathol, 12, 29-224 (1978).

3) D. V. Lightner and C. T. Fontaine: J. Inver. Pathol., 25, 239-245 (1975).

4) M. A. Solani and D. V. Lightner: J. Inver. Pathol., 27, 77-86 (1976).

5) C. D. Burns, M. E. Berrigan and G. E. Hinderson: Aquaculture, 16, 193-198 (1979).

6) K. Hatai and S. Egusa: Fish Pathol, 12, 225231 (1978).

7) D.J. Alderman: Trans. Br. Mycol. Soc., 76, 25-27 (1981).

8) M. Chianain and A. Vey: Dis. Aqua. Organism., 5, 215-223 (1988).

9) A. Colorni: Mycopathologia, 108, 145-147 (1989),

10) J. E. Hose, D. V. Lightner, R. M. Redman and D. A. Donald: J. Inver. Pathol, 40, 292-302 (1984).

11) D. V. Lightner and R. M. Redman: J. Inver. Pathol., 30, 298-302 (1977).

12) B. Z. Bian and S. Egusa: Trans. Br. Mycol. Soc., 76, 25-27 (1981).

13) K. Momoyama: Fish Pathol., 22, 15-23 (1987).

14) C. Booth: The Genus Fusarium, 1st ed., Commonwealth Mycol. Inst., Kew Surrey, England, 1971, pp. 122-132.

15) P. E. Nelson, T. A. Toussoun and W. F. O. Marasas: Fusarium species; An Illustrated Manual for Identification, 1st ed., Pennsylvania State University Press, 1983, pp. 128-150.

16) N. A. Young, K. J. Know-chung, T. T. Kubota, A. E. Jenning and R. I. Fisher: J. Cli. Microbiol., 7, 589-594 (1978).

17) P. F. Frelier, L. Singler, P. E. Nelson: J. Med. Vet. Mycol., 23, 399-402 (1985).

18) M. S. Collin and M. G. Rinalde: Sabourardia, 
15, 151-160 (1977).

19) C. H. June, P. G. Beatty, H. M. Shulman and M. G. Renaldi: Southern Med. J., 79, 513-515
(1986).

20) D. J. Alderman and C. T. Fontaine: J. Fish Dis., 8, 249-252 (1985). 